\title{
Time-Related Anticoagulation after Regional and Systemic Administration of Heparin in Patients Undergoing Aortoiliac Surgery
}

\author{
Bengt Lindblad ${ }^{1}$, David Bergqvist ${ }^{1}$, Thomas W. Wakefield ${ }^{2}$ and James C. Stanley ${ }^{2}$ \\ ${ }^{1}$ Department of Surgery, Lund University, Malmö General Hospital, Malmö, Sweden and the ${ }^{2}$ Section of Vascular \\ Surgery, Department of Surgery, University of Michigan Medical Center, Ann Arbor, Michigan, U.S.A.
}

\begin{abstract}
Heparin anticoagulation during cardiovascular surgical procedures remains poorly investigated and understood. The objective of this investigation was to assess the effectiveness of three methods of heparin administration. Heparin sulfate (75 $I U / \mathrm{kg}$ ) administered to patients undergoing aortoiliac surgery was randomised to one of three methods: Group I $(\mathbf{n}=9)$ heparin was injected into a central venous line 5 minutes before infrarenal aortic clamping; Group II $(\mathrm{n}=9)$ heparin was injected into the distal aneurysm immediately after infrarenal aortic clamping; and Group III $(\mathrm{n}=8)$ heparin was injected into a central venous line immediately after infrarenal aortic clamping. Blood samples were analysed for anticoagulant activity from both the upper and lower extremities at 5, 15,30,60, and 120 minutes after heparin administration. Anticoagulation, as measured by aPTT, antifactor Xa levels, and ACT, was achieved in all three groups by 5 minutes, but initially with lower heparin activity (measured as antifactor Xa) in the upper extremity (Group II) and lower extremity (Group III), respectively. These differences were also evident in ACT and aPTT determinations. Intravenous heparin administration prior to aortic cross-clamping achieves excellent anticoagulation (anti-factor $\mathrm{Xa} \sim 1 \mathrm{U} / \mathrm{ml}$ ) in both upper and lower extremities after 5 minutes. With regional administration, rapid heparin redistribution occurs, but it takes longer to achieve the same level of anticoagulation distant from the site of administration. Nevertheless, from a practical perspective the method of administration does not appear to have a great influence on the eventual achievement of adequate anticoagulation.
\end{abstract}

Key Words: Heparin; Anticoagulation; aPTT; Antifactor Xa; ACT; Randomized controlled trial.

\section{Introduction}

Intraoperative thrombosis may complicate major cardiovascular reconstructions, especially those involving aortic cross-clamping. Heparin sulfate is used to prevent such thrombotic complications. However, opinions vary widely among surgeons about the time interval after heparin administration that is necessary before adequate anticoagulation is achieved. The route of administration in relation to aortic cross-clamping, intravenous versus intra-aortic, is also a point of frequent discussion. Likewise, it is not known if it is worthwhile to repeat heparin administration during aortic cross-clamping and if such administration will be properly redistributed. This study focuses on the time-related effects of heparin administration during

Please address all correspondence to: Bengt Lindblad, Department of Surgery, Lund University, Malmö General Hospital, S-21401 Malmö, Sweden. aortic cross-clamping in patients undergoing vascular surgery.

\section{Material and Methods}

Twenty-six patients undergoing elective infrarenal aortic aneurysmectomy were randomly allocated to three study groups: Group I $(n=9)$ were given $75 \mathrm{IU} /$ $\mathrm{kg}$ heparin intravenously into a central venous catheter 5 minutes prior to aortic clamping; Group II $(n=9)$ were given $75 \mathrm{IU} / \mathrm{kg}$ heparin into the aneurysm at the time of aortic clamping; and Group III $(n=8)$ were given $75 \mathrm{IU} / \mathrm{kg}$ heparin intravenously into a central venous catheter at the time of aortic clamping. The groups were well matched with no significant differences regarding age (mean age 73 years), gender, or operative blood loss (mean 1,800 ml), fluid administration and intraoperative transfusion requirements. 
During the operation $500 \mathrm{ml}$ dextran (Rheomacrodex $^{\circledR}$, Pharmacia AB, Uppsala, Sweden) was administered over a 3 to 4 hour period of time. Citrated blood samples from one radial artery and one femoral vein were obtained as baseline values just prior to heparinisation and 5, 15, 30, 60, and 120 minutes thereafter. Activated clotting time (ACT, maximum 400 seconds) was assessed using tubes containing 12 $\mathrm{mg}$ diatomaceous earth and a small magnet. The ACT was determined in seconds with an electronic clot timer (Hemochron, International Technydine Corp, Metuchen, NJ, U.S.A.). Additional plasma samples were frozen and analysed later for aPTT and antifactor Xa levels using a chromogenic substrate technique. All analyses were performed at the Department for Coagulation Disorders, Malmö General Hospital, Lund University, Malmö, Sweden.

The study was approved by the Ethics Committee, Lund University. Statistical analyses included analyses of variance (ANOVA) for non-parametric data and Student's $t$-test for differences between groups; $p<0.05$ was considered significant.

\section{Results}

Equal prolongation of ACT after 5 minutes was obtained in Group I in the upper and lower extremities, but in Groups II and III higher levels $(p<0.05)$ were seen after 5 minutes in the lower (II) and upper

Table 1. ACT levels in vascular surgery patients

\begin{tabular}{llll}
\hline & Group I & Group II & Group III \\
\hline Upper extremity & & & \\
Baseline & $160 \pm 4$ & $160 \pm 7$ & $167 \pm 7$ \\
5 min & $276 \pm 17$ & $222 \pm 16$ & $292 \pm 22$ \\
15 min & $272 \pm 13$ & $235 \pm 11$ & $264 \pm 13$ \\
30 min & $269 \pm 16$ & $243 \pm 11$ & $270 \pm 16$ \\
60 min & $225 \pm 12$ & $230 \pm 18$ & $242 \pm 15$ \\
120 min & $203 \pm 10$ & $215 \pm 15$ & $221 \pm 21$ \\
& & & \\
Lower extremity & & & \\
Baseline & $164 \pm 6$ & $159 \pm 10$ & $165 \pm 8$ \\
5 min & $262 \pm 15$ & $263 \pm 33$ & $231 \pm 22$ \\
15 min & $278 \pm 17$ & $299 \pm 33$ & $264 \pm 18$ \\
30 min & $261 \pm 10$ & $310 \pm 25$ & $251 \pm 14$ \\
60 min & $252 \pm 17$ & $255 \pm 27$ & $259 \pm 12$ \\
120 min & $193 \pm 7$ & $212 \pm 25$ & $202 \pm 31$ \\
\hline
\end{tabular}

Group I central venous heparin administration 5 minutes before aortic clamping; Group II intra-aneurysmal heparin administration at aortic clamping; Group III central venous heparin administration at aortic clamping, (Mean \pm S.D.)

(III) extremities, respectively (Table 1). This was also evident in differences in antifactor Xa levels (Figs 1 to

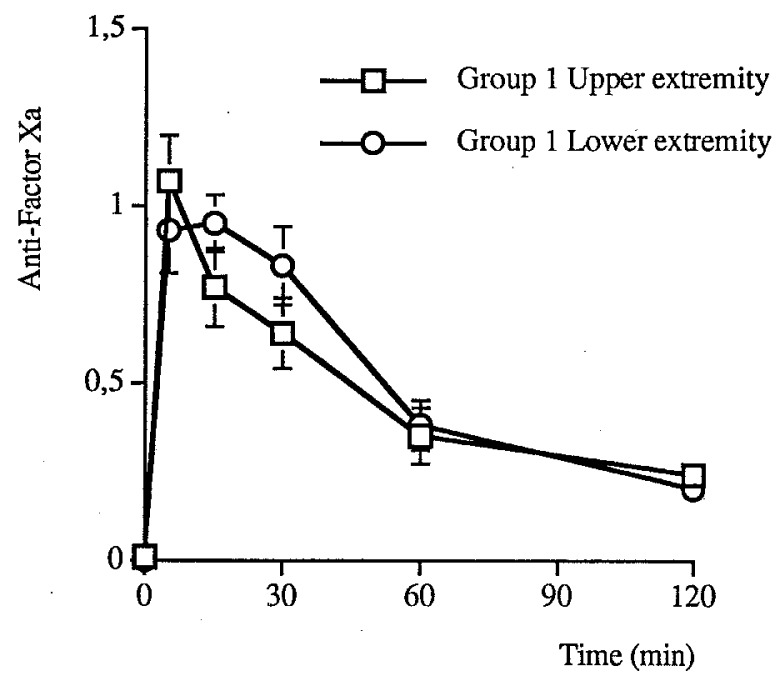

Fig. 1. Anti-Factor $\mathrm{Xa}$ activity following central venous heparin administration 5 minutes before aortic clamping (Group I).

3). The highest heparin level achieved was approximately $1.2 \mathrm{unit} / \mathrm{ml}$. The aPTT levels showed no difference between upper and lower extremity samples in group I, whereas there was a tendency in the lower and upper extremities in Groups II and III, respectively, for the values to be higher (Table 2). The antifactor Xa levels remained slightly elevated after 120 minutes to about $0.2 \mathrm{IU} / \mathrm{ml}$. However, the aPTT levels showed a more marked prolongation 120 minutes after heparin administration. Blood samples from the femoral vein 15 minutes after heparin administration in one patient were not obtained, and in another two patients heparinisation was reversed within 60 minutes. No difference in baseline values were seen between venous and arterial blood samples.

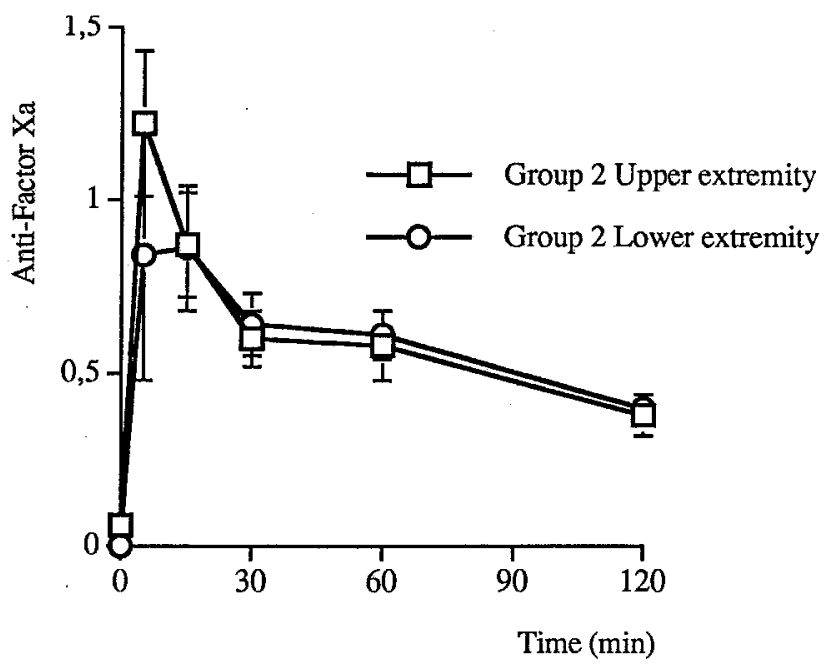

Fig. 2. Anti-Factor Xa activity following intra-aneurysmal heparin administration at the time of aortic clamping (Group II). 


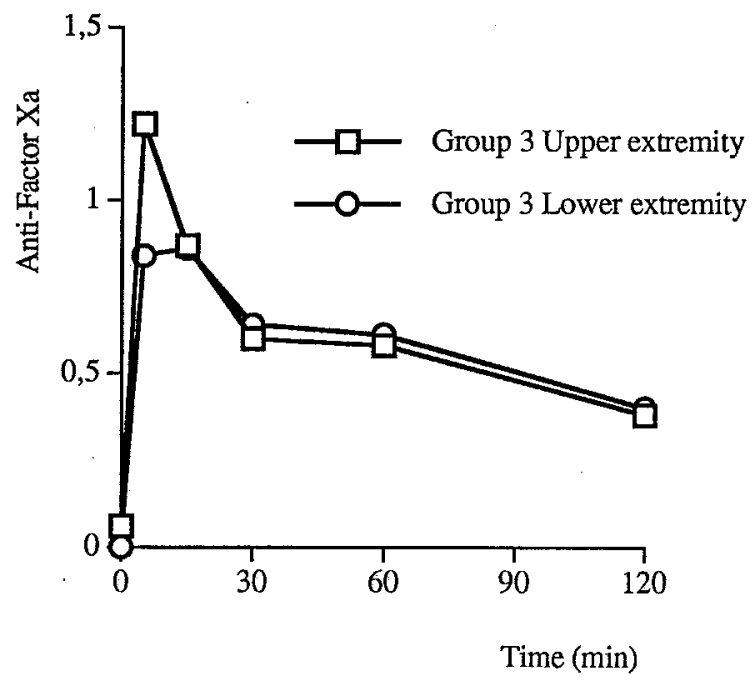

Fig. 3. Anti-Factor $\mathrm{Xa}$ activity following central venous heparin administration at the time of aortic clamping (Group III).

\section{Discussion}

Recent articles dealing with heparin dynamics document a wide variety of results regarding anticoagulation during cardiovascular surgery. ${ }^{1,2}$ Heparin given intravenously has an in vivo half-life that is considered dose-dependent. ${ }^{3 .}$ Some studies have demonstrated a quick rise to maximum ACT and prothrombin-time values within 1 minute after heparin administration, ${ }^{4}$ while others suggest a much longer time is necessary to achieve adequate anticoagulation. ${ }^{5}$ Effeney and colleagues found that maximum anticoagulation following heparin administration occurred in 5 to 24 minutes in peripheral vascular surgery patients, com-

Table 2. APTT levels in vascular surgery patients

\begin{tabular}{llll}
\hline & Group I & Group II & Group III \\
\hline Upper extremity & & & \\
& & & \\
Baseline & $39 \pm 2$ & $49 \pm 8$ & $42 \pm 3$ \\
5 min & 300 & $182 \pm 45$ & $283 \pm 17$ \\
15 min & 300 & $275 \pm 26$ & 300 \\
30 min & $261 \pm 26$ & $280 \pm 20$ & $273 \pm 27$ \\
60 min & $205 \pm 44$ & $246 \pm 36$ & $259 \pm 28$ \\
120 min & $160 \pm 51$ & $227 \pm 46$ & $212 \pm 65$ \\
& & & \\
Lower extremity & & & \\
& & & \\
Baseline & $41 \pm 3$ & $44 \pm 7$ & $42 \pm 2$ \\
5 min & 300 & $261 \pm 36$ & $184 \pm 44$ \\
15 min & 300 & 300 & $261 \pm 26$ \\
30 min & 300 & 300 & 300 \\
60 min & $240 \pm 39$ & $262 \pm 32$ & 300 \\
120 min & $146 \pm 46$ & $216 \pm 52$ & $211 \pm 53$ \\
\hline
\end{tabular}

Group I central venous heparin administration 5 minutes before aortic clamping; Group II intra-aneurysmal heparin administration at aortic clamping; Group III central venous heparin administration at aortic camping, (Mean \pm S.D.). Maximum value was 300 seconds. pared to 10 to 34 minutes in cardiac surgery patients. ${ }^{6}$ This is in contrast to our findings where adequate anticoagulation was obtained within minutes after heparin administration, with less initial prolongation in areas distant from the site of administration. However, in our studies heparin distribution and adequate anticoagulation was universally achieved in all instances by 15 minutes. It seems reasonable to assume that repeat heparin administered during a vascular procedure will be distributed also to tissues beyond a clamped vessel. In a canine study using similar methods of heparin administration as in the present study, complete anticoagulation was achieved within 5 minutes with all three methods of administration in both upper and lower extremities. ${ }^{7}$

We assessed the state of anticoagulation using the $\mathrm{ACT}$ test, since it is frequently used intraoperatively to establish the effectiveness of anticoagulation. The ACT responds in a linear fashion to increasing heparin dosage and correlates well with observed clinical anticoagulation, such as with use of thrombus-free cardiopulmonary bypass equipment. ${ }^{8}$ Adequate anticoagulation for extracorporeal circulation is defined as an ACT prolongation of more than 480 seconds, but most clinicians would agree that any value between 300 and 600 seconds is acceptable. ${ }^{9}$ For most peripheral vascular procedures, values between 200 and 250 seconds are considered appropriate. This level of anticoagulation was promptly achieved in our study and maintained during the 120 minute followup. Likewise, accepted adequate anticoagulation may be defined by an aPTT of 2.5 or greater than control values. $^{10,11}$ As was the case with ACT levels in the present study, these aPTT values were achieved and maintained throughout the 120 minute followup.

Heparin effects were also determined in the present study by measuring the antifactor Xa levels. Maximal values measured were slightly greater than 1 $\mathrm{U} / \mathrm{ml}$, which are in accordance with findings of others, ${ }^{12,13}$ although our decline of antifactor Xa levels was slightly less than reported earlier. Antifactor Xa levels at 120 minutes in our study were approximately $0.2 \mathrm{U} / \mathrm{ml}$, while others using a slightly higher heparin dose observed a lower peak level, but values of approximately $0.4 \mathrm{U} / \mathrm{ml}$ at 120 minutes. ${ }^{12}$ The accepted range of heparin activity for effective anticoagulation is between 0.2 and 1.0 antifactor $\mathrm{Xa} \mathrm{U} / \mathrm{ml}$ plasma, which was achieved during the 120 minute period after heparin administration in the current study.

This study supports the tenet that adequate anticoagulation during aortic reconstructive surgery is obtained within 5 minutes after systemic heparin administration. Regional heparin administration at the time of aortic cross-clamping requires slightly 
longer time for heparin distribution and subsequent adequate anticoagulation in both the upper and lower extremities. Aortic cross-clamping can be safely performed at 5 minutes after heparin administration, and extrapolating from previously reported canine data probably can be performed as early as 1 minute after intravenous heparin administration. Heparin distribution after regional administration suggests that repeated administration during prolonged vascular occlusions should allow for adequate anticoagulation distal to the clamped vessel, albeit with a longer period of time necessary to achieve maximum anticoagulation.

\section{Acknowledgements}

This study was supported by a Swedish Medical Research Foundation (00759) grant.

\section{References}

1 Hirsh J, van-Aken WG, Gallus as, Dollery CT, Cade JF, Yung WL. Heparin kinetics in venous thrombosis and pulmonary embolism. Circulation 1976; 53: 691-695.

2 McAvor TJ. Pharmocokinetic modeling of heparin and its clinical implications. J Pharmacokinet-Biopharm 1979; 7: 331-354.
3 O'Reilly RA. Anticoagulant, antithrombotic and thrombolytic drugs. In Goodman LS, ed., The Pharmacological Basis of Therapeutics. MacMillan 1985; 1338-1344.

4 AKl BF, Vargas GM, Neal J, Robillard J, Kelly P. Clinical experience with the activated clotting time for the control of heparin and protamine therapy during cardiopulmonary bypass. J Thorac Cardiovasc Surg 1979; 79: 97-102.

5 Doty DB, KNotT HW, Hoyt JL, KoEpke JA. Heparin dose for accurate anticoagulation in cardiac surgery. J Cardiovasc Surg 1979; 20: 597-604.

6 Efreney DJ, Goldstone J, Chin D, Krupsia WC, Ellis RJ Intraoperative anticoagulation in cardiovascular surgery. Surgery 1981; 90: 1068-1074.

7 Vincent CK, Wakefield TW, Lindblad B, Stanley JC, Fleming AW. Time-related effects of heparin sulfate on regional and systemic anticoagulation. J Natl Med Assoc 1992; 84: 961-964.

8 Stenbjerg S, Berg E, Albrechtsen OK. Heparin levels and activated clotting time (ACT) during open heart surgery. Scand J Haematol 1981; 26: 281-284.

9 Bull BS, Huse WM, Brauer FS, Korpman RA. Heparin therapy during extracorporeal circulation. II. The use of a dose-response curve to individualize heparin and protamine dosage. $J$ Thorac Cardiovasc Surg 1975; 69 685-689.

10 BRANDT JT, TRIPPLETT DA. Laboratory monitoring of heparin. Effects of reagents and instruments on the activated partial thromboplastin time. Am J Clin Pathol 1981; 76: 530-537.

11 Manny J, Romanoff H, Hxam E, Manny N. Monitoring of intraoperative heparinization in vascular surgery. Surgery 1976; $80641-643$.

12 Perry MO, Horton J. Kinetics of heparin administration. Arch Surg 1976; 111: 403-409.

13 Porte RJ, de Jong E, Knot EAR, de MaAt MP, Terpstra OT, VanURK $H$, GROENLAND TH. Monitoring heparin and haemostasis during reconstruction of the abdominal aorta. Eur J Vasc Surg 1987; 1: 397-402.

Accepted 2 February 1994 